\title{
The participatory turn in health and medicine: The rise of the civic and the need to 'give back' in data-intensive medical research
}

\author{
Lotje E. Siffels (10 ${ }^{1,2 \times}$, Tamar Sharon ${ }^{1,2} \&$ Andrew S. Hoffman ${ }^{1,2}$
}

What has been called the "participatory turn" in health and medicine refers to a general shift from paternalistic and hierarchical, to more collaborative and egalitarian relationships between medical experts and patients/research participants; a shift from what the pragmatic sociologists Boltanski and Thévenot (2006) call a "domestic" to a "civic" order of worth. Critical scholarship on the participatory turn tends to emphasize discrepancies between ideals of equality and empowerment, and practices of increased individual responsibility and disempowerment. In this paper, we depart from this critical literature by suspending evaluation about authentic and inauthentic ideals and practices. Instead, we explore the issues and challenges that arise in the process of ensuring that ideal and practice align in what we call a civic-participatory style of doing medical research. Drawing on interviews and observations carried out with medical researchers, coordinators and assessors in a longitudinal cohort study called the Personalized Parkinson's Project (PPP), we show that for study staff it is often unclear how they can meet the demands of reciprocity towards research participants that are presupposed by civic-participatory ideals. In particular, in the context of a study whose aim is the creation of a comprehensive dataset comprised of clinical, environmental and lifestyle data that study participants generously "give" over a period of 2 years, we observed a persistent concern on the part of study staff regarding what and how to "give back". As we show, study staff negotiate and resolve this tension through recourse to creative workarounds and innovative ways of giving back, including frequent project and scientific updates, newsletters, the designation of personal assessors and pampering Event Days. The paper makes a contribution to the critical literature on the participatory turn by showing the utility of the orders of worth framework in probing the challenges and workarounds that emerge in settings where an incumbent style of organizing medical research (here, the 'civic') comes to challenge practices hitherto organized according to a wholly different logic (in this case, the 'domestic')-without making assumptions about the (in) authenticity of such ideals and practices. Moreover, we contend that this framework offers new tools for evaluating participatory research projects in the form of "good" or "successful" civic-domestic compromises. 


\section{Introduction}

n September 25, 2020, the second annual Personalized Parkinson's Project (PPP) Event Day was held at the Vereeniging concert hall in the Dutch city of Nijmegen, a majestic national heritage building rivalled in the Netherlands only by Amsterdam's renowned Concertgebouw for the quality of its acoustics. After the event's initial cancellation in March 2020 due to the COVID-19 pandemic, the event organizers seized the opportunity of a period of relaxed lockdown measures to host what many of the participants in the PPP held to be one of the highlights of this medical research study, and what many of the study staff viewed as an important way of giving something back to study participants. The full-day event had a rich programme of updates about the study, lightning talks on state-of-the-art Parkinson's research from world renowned scientists, a dance session tailored to individuals with Parkinson's disease, a discussion devoted to tips on living with Parkinson's from various fields of expertise, much time for Q\&A, and an elaborate lunch. Pandemic restrictions meant that capacity was limited to 250 (versus 700), drinks would not be served in the building's magnificent foyer at the end of the day, and many of the eminent speakers from around the globe would swap physical for digital presence. Despite these limitations, the central message of the event remained clear: the real heroes of the PPP are its participants, and they deserved some gratitude.

The PPP is a prospective, longitudinal cohort study in which 520 individuals living with Parkinson's disease (PD) are followed over the course of two years. During this time, various types of clinical, physiological and environmental data are collected to create an extensive dataset for the discovery of new biomarkers and new targets for therapeutic interventions. The PPP is funded by Verily Life Sciences LLC, Radboud University Medical Center (RUMC), Radboud University, the city of Nijmegen and the Province of Gelderland. Several features make the PPP stand out in relation to other PD cohort studies, as the study's protocol expounds (Bloem et al., 2019). First, the database it aims to create is expected to be far more comprehensive than any other PD research database currently in existence. Second, all assessments take place at one site, the RUMC. Third, the integration of continuous monitoring with a wearable extends data collection into the free-living environment. Fourth, the study touts a novel privacy- and security-by-design infrastructure for exchanging participant data (Jacobs and Popma, 2019). Finally, the PPP is undergirded by an ethos of patient-centeredness and a participatory approach to medical research. From the involvement of an advisory panel of Parkinson's patients for the duration of the study, to a website, newsletters and videos that share updates and information with participants, to the indulgent PPP Event Days, patient-centeredness and participation have imbued the way the study has been designed and is daily coordinated.

In line with this, the PPP can be understood as an illustrative example of what many scholars refer to as the "participatory turn" in health and medicine (Beier et al., 2019; Eysenbach, 2008; Hood, 2009; Nielsen and Langstrup, 2018; Prainsack, 2011, 2014, 2017; Topol, 2016; Wyatt et al., 2013), characterized by a flattening of hierarchies between medical experts and patients/research subjects. As we will discuss in more detail below, the PPP can thus also be understood in terms of a shift from a "domestic" to a "civic" order of worth in the terminology of pragmatic sociology (Boltanski and Thévenot, 2006). Here a domestic "style" (Eliasoph and Lichterman, 2003) of doing medical research and healthcare-characterized by hierarchical and paternalistic relationships between medical experts and patients-gives way to a more civic one, where patients are reconfigured as co-equal participants and collaborators in research and care.
It is this "civic-participatory" style of doing research inherent to the PPP that is the focus of this paper. In particular, we are interested in the new demands that it puts on study staff-those professionals who are responsible for the day-to-day operations of the PPP - and how these are negotiated. What happens, in other words, when a civic-participatory style of doing medical research becomes dominant in a context which has traditionally been organized domestically? What tensions does this give rise to in the PPP, which was designed from the outset to embody civic ideals of participatory health and medicine? And how are these tensions resolved? We draw on a range of material to show how this emergent civic-participatory style inheres in the everyday conduct of the PPP, influencing how study staff understand their role and conditioning their engagement with participants. Our material includes six in-depth, semi-structured interviews with PPP study staff as well as (participant) observations conducted at PPP events in early-mid 2020 and content analysis of PPP-related documents. What we call "study staff" includes the project's principal investigator, junior and senior researchers, a project manager, a communication officer, a patient engagement lead, as well as assessors; specialized nurses who carry out the assessments and are the primary contact persons for the participants of the study.

Importantly, our empirical data reveals that enacting the "civic" in a domain that has traditionally been organized "domestically" is no easy task. This is because participation in the PPP requires a high level of involvement on the part of participants, who over a period of two years are asked to take part in several demanding assessment days and to contribute substantial amounts of clinical, physiological and environmental data that are collected on a daily basis via a wearable they are required to wear for the duration of the study. In a domestic, or what we might call "pre-participatory" research setting, such contributions on the part of participants would mostly be taken for granted. But within a civic-participatory one, which assumes more equal and reciprocal relations between participants and researchers, these substantial contributions-or the fact that participants "give so much," as one study staff member phrased it-create a strong desire on the part of the study staff to reciprocate, or to "give back". Yet, because the PPP seeks first and foremost to compile a comprehensive dataset which will only subsequently be used to develop personalized Parkinson's treatments at some later moment, study staff are limited in what they can give back. In other words, without being able to offer study participants either curative/palliative interventions, or else actionable insights derived from the data collected over the course of their participation in the study, study staff feel that their hands are tied. As we show, in order to resolve this tension, this latter group find a number of creative workarounds and innovative ways of "giving back", including frequent project and scientific updates, newsletters, the designation of personal assessors, proclamations of gratitude, pampering Event Days, and personalized Christmas cards, among others.

Our analysis of how the new demands of the civic-participatory are addressed in the PPP aims to contribute to the critical literature that seeks to understand the effects of what we call the civic-participatory turn in health and medicine. However, we depart from this literature in two important ways. First, while critiques of the participatory turn tend to focus on its effects on patients and research participants, our empirical investigations signal that the participatory turn is not only consequential for those receiving care but also those providing it-in our case, the study staff who are responsible for the day-to-day operations of the PPP. Secondly, critical scholarship on the participatory turn tends to emphasize-and attempts to reveal-a persistent 
discrepancy between an idealistic rhetoric of participation, equality and empowerment, and practices of increased individual responsibility and disempowerment (Prainsack, 2014; Wyatt et al., 2013; Sharon, 2017). Instead, and in line with the ethos of Boltanski and Thévenot's pragmatic sociology of critical capacity, we move away from an assumed distinction between authentic and inauthentic ideals and/or practices, and focus on the practical and material effects that transpire when actors seek to coordinate their efforts according to a civic style of doing medical research.

We contend that Boltanski and Thévenot's 'pragmatic' approach-which implies both a value pluralism in the form of multiple orders of worth, and thus the likelihood of agonism, in which different orders clash, compete, and become dominant in different settings at different times-promises significant analytic purchase here. The orders of worth framework is well-suited for probing the myriad challenges and workarounds that emerge in the process of the rise to dominance of one order where another order had been prevalent (Sharon, 2021). Moreover, because the orders of worth framework also suggests that clashes of orders can result in "compromises" about what is considered good or right in a given setting, the approach also furnishes an analytic lexicon that accounts for the simultaneous co-presence of different registers of value and the implications of combinations between them (cf. Berg and Mol, 1998; Law and Mol, 2002). Indeed, we conclude that the PPP may best be described as a civic-domestic compromise, where domestic values of hierarchy and esteem have in effect been expunged to make room for the civic values of equality and reciprocity, but where residual values of the domestic order, namely care and responsibility, persist and comingle with the civic.

The article proceeds as follows. First, we briefly review the socalled participatory turn in health and medicine and requalify this as a shift from a domestic to a civic style of doing research. We then describe the tension that the rise to dominance of the civic in a traditionally domestic context leads to, as seen in the framework of the PPP in the form of study staff s perceived need to give back. We then show how study staff resolved this tension by finding creative ways of giving back. We use Nancy Fraser's (1998) twodimensional conception of justice as "parity of participation" to understand these many ways of giving back in terms of, on the one hand, "information provision as redistribution" and, on the other, "acknowledgement as recognition". We conclude with a section that discusses the added value of the orders of worth framework for understanding the effects of the participatory turn in light of our fieldwork. Drawing on the value pluralism and value agonism that are at the core of this framework, we contend that it offers new tools for evaluating participatory research projects in the form of "good" or "bad" civic-domestic compromises.

\section{The PPP: A civic-participatory style of organizing research}

\section{The participatory turn and the PPP. As briefly discussed above,} in recent decades, "participation" has become a central concept in healthcare and medical research, leading to what many STS and critical health scholars have identified as a "participatory turn" (Beier et al., 2019; Eysenbach, 2008; Hood, 2009; Nielsen and Langstrup, 2018; Prainsack, 2011, 2014, 2017; Topol, 2016; Wyatt et al., 2013). While different models and meanings of participation for health and medicine abound, three central features are prominent in this new participatory paradigm, all three of which are prevalent in the PPP. First, a flattening out of existing hierarchies between medical experts and patients and the establishment of more equal relations between them (Hood, 2009; Topol, 2016, p. 12; cf. Collins et al., 2007). Second, a requalification of patients from passive recipients of care to proactive citizen-patients who, armed with greater levels of information, can participate in collaborative decision-making (Kremer et al., 2011; Sharon, 2015; Wyatt et al., 2010). Third, an appreciation for patients' lay expertise as equally valid as other forms of expertise (Epstein, 1995, p. 409; Pols, 2014; Prior, 2003; Myskja, 2007; Rabeharisoa, 2003).

Each of these features are important characteristics of the PPP. First, the PPP clearly seeks to overturn existing hierarchies between researcher and research subjects. For example, the study staff refrain from using the term "patient" when referring to individuals participating in the PPP. As one study staff member recounted during an interview, 'We don't use that term anymore, "patient" [...] A patient is something pathetic, something waiting, something passive. And a participant is an active person.'[C122] ${ }^{12}$ Second, the project's study protocol was developed in collaboration with a panel of 20 individuals living with Parkinson's, which continues to advise the research team (Bloem et al., 2019), just as participants are frequently invited to answer surveys about the study. Third, the PPP emphasizes that participants are experts in their own right, based on their intimate experiences of living with $\mathrm{PD}$ and their knowledge about compensating for the disease.

Importantly in this regard, the PPP is the brainchild of Prof. Bastiaan ["Bas"] Bloem, an internationally renowned neurologist at RUMC who is both an expert in PD, a champion of participatory medicine, and the PPP's Principal Investigator. Bloem's advocacy for participatory medicine stretches back well before the PPP and beyond the clinic walls to more public-facing engagement around the issue. Consider, for instance, his appearance at a TEDxMaastricht event in 2011, where a talktellingly entitled "From God to Guide"-begins with Bloem standing on an elevated forklift platform where he is talking down, as it were, to Hans, a patient with PD. Hans proclaims a desire to have a part in making decisions about his care, and finding other patients like himself to make things better, whereupon Bloem descends from his tower to tell Hans that the world he has created is one where 'there is no more hierarchy.' Bloem's talk goes on to articulate a 'world of participatory healthcare' where 'doctors and patients are working together on a mutual basis,' where 'we have mutual respect and collaborate with each other' and where patients are not 'passive objects' but are rather 'active subject[s]' in their own care (Bloem, 2011).

From a "domestic" to a "civic" style of doing research. What STS and critical health scholars have identified as the participatory turn can be recast in the terminology of pragmatic sociology as a transition from a "domestic" to a more "civic" style of organizing medical research. Here we draw on the work of Boltanski and Thévenot (2006), who outline a typology of what they call "orders of worth": coherent vocabularies of argumentation and justification that are organized around different visions of the common good. Each order furnishes a set of conventions, justificatory principles, and evaluative criteria which guide coordinated action. In their book On Justification, the authors identify six such orders of worth (see Table 1). Importantly, these stand in uneasy tension with one another. Their model is thus an agonistic one, where one order frequently wins out over and above another, although there is also the possibility for new "compromises" between orders to be reached, resulting in hybrid situations and qualifications.

Of the six orders, it is the "domestic" and "civic" orders which are of greatest interest in the current analysis. ${ }^{3}$ The domestic order of worth values hierarchical relations, familial ties and tradition. It implies both respect, reverence and dependency from those on the lower end of the hierarchy to those higher up, as well 
Table 1 Orders of worth (based on Boltanski and Thévenot, 1999, p. 368).

\begin{tabular}{|c|c|c|c|c|c|c|}
\hline & Domestic & Civic & Market & Industrial & Opinion & Inspired \\
\hline $\begin{array}{l}\text { Format of relevant } \\
\text { information }\end{array}$ & $\begin{array}{l}\text { Oral, exemplary, } \\
\text { anecdotal }\end{array}$ & $\begin{array}{l}\text { Formal, } \\
\text { official }\end{array}$ & Monetary & $\begin{array}{l}\text { Measurable: criteria, } \\
\text { statistics }\end{array}$ & Semiotic & Emotional \\
\hline Elementary relation & Trust & Solidarity & Exchange & Functional link & Recognition & Passion \\
\hline Human qualification & Authority & Equality & $\begin{array}{l}\text { Desire, } \\
\text { purchasing power }\end{array}$ & $\begin{array}{l}\text { Professional } \\
\text { competency, expertise }\end{array}$ & Celebrity & Creativity, ingenuity \\
\hline
\end{tabular}

as duties and responsibilities from those at the higher end to those below. Paternalism is not so much a bug as it is a feature of the domestic order. In the context of health and medicine, this hierarchical relationship of dependency of patients on medical experts and clinical staff is an important part of the provision of the care as it should be. In this sense one could say that a domestic style is characteristic of "pre-participatory-turn" health and medicine. On the other hand, the "civic" order of worth values equality, solidarity, and democratic process. A relationship in this order should be equal and collaborative. In the context of health and medicine, the civic implies that patients and doctors are coequal, dependency and hierarchy giving way to shared decision making and collective action. The PPP, from this perspective, can be construed as a civic-participatory endeavour.

The added value of the orders of worth framework. We contend that there is significant added value in deploying the orders of worth framework to understand the dynamics and stakes of the PPP. Much recent scholarship has approached the participatory turn with great scepticism. Critiques include discussions of the general muddiness of the very concept of "participation" (Prainsack, 2011; Woolley et al., 2016, Corrigan and Tutton, 2006; Beier et al., 2019); the way in which this new paradigm creates new types of work and responsibility for patients, while lessening the burden for states and collectives (Dickenson, 2013; Prainsack, 2009, 2011, 2014, 2017; Petersen and Lupton, 1996); and how "participation" rhetoric is used as a mere means for achieving more nefarious ends of cost-cutting and facilitating streamlined personal data collection for the purposes of boosting profits of private firms (Harris et al., 2013; Wyatt et al., 2010)—all the while leaving critical aspects of "care" by the wayside (Mol, 2008; Dickenson, 2013).

Throughout this body of scholarship, we see critiques of the participatory turn hinge on arguments that "civic" discourses of participation are being used instrumentally for realizing "noncivic" ends, and thus the analytic task is to unmask the participatory turn as inauthentic (Hansen, 2016; Latour, 2004; Lehtiniemi and Ruckenstein, 2019; Sharon, 2017). Although these contributions are valuable for drawing our attention to how these changes in the conduct of medical care and research stand to negatively impact patients and citizens, our own study has important differences, both conceptually and empirically.

Conceptually, a main affordance of Boltanski and Thévenot's orders of worth framework in this setting lies in how it helps us to identify the effects of the rise of a particular order of worth-in our case, the "civic"-in a setting where an incumbent "domestic" order had long served to structure the delivery of care. Indeed, Boltanski and Thévenot's moral universe is a pluralistic and agonistic one, where orders clash and compete. Drawing on the work of 17th century philosopher Blaise Pascal's notion that "tyranny consists in the desire to dominate everything regardless of order" (Boltanski and Thévenot, 2006, p. 104), Boltanski and Thévenot speak of extensions of orders beyond their "legitimate" boundaries, of contestable "importations" and "transportations" of worth from one to another order, and of "confusions" of orders that arouse a sense of injustice.

Building on the notion that orders of worth travel, and that they can be more or less dominant in different material and temporal contexts, in this article, we ask what happens when a "civic" style of doing medical work, in which participatory discourses and practices configure patients as coequals in care and research, comes to challenge a "domestic" style. We ask, what tensions does this give rise to in the PPP, which was designed from the outset to embody civic ideals of participatory health and medicine? And how are these tensions resolved? This leads to an important empirical difference of our study, as well. When we ask about the effects of the participatory turn, and of the challenges of conducting a civic-participatory style of medical research as enacted by the PPP, our focus here is not on participants or patients-as is the case with much of the literature we review above. Rather we interrogate the effects this shift has on the PPP study staff, and especially the medical assessors and project managers who carry out the routine work of coordinating and running the project.

In sum, our objective here is to unpack the effects of the participatory turn if and when these do transpire-that is, when civic ideals are not thwarted, re-routed or used instrumentally, but when they more or less "succeed" in the eyes of those carrying out this work. We thus shift our gaze from patients to "experts" in the participatory relationship, and we shift the emphasis of our analysis from unfulfilled promises to the effects of promises on practitioners. This comes with significant added value, as we shall show, since taking this as our starting point allows us to interrogate the issues and challenges that arise in the process of ensuring that discourse and practice align in a "civic" style of doing medical research, as well as the workarounds that study staff deploy as they seek to realize the promises of the participatory turn.

Methodology. The data and analysis presented in this paper are drawn from an ongoing multi-sited investigation into the ethical and societal implications of the digital disruption of health research called "Digital Good", funded by the European Research Council. The PPP is one of several case studies within this broader project. Initial access to the PPP was facilitated by preestablished research ties between researchers within both projects, and interest on the part of the PPP's Principal Investigator in how insights from philosophy and STS could be brought to bear on the PPP.

In this way, our own relationship with the PPP is meant to be reciprocal: for instance, a series of feedback sessions were planned into the initial design of our project, where our research team 
would share ongoing findings with PPP study staff as points of critical engagement with their own practices of organizing dataintensive participatory research. Manuscript drafts (including this one) are also shared with study staff, both as a check on the veracity of our claims but also as a means of keeping them informed about the conclusions we draw from observing their work. Moreover, as is often the case with qualitative and ethnographic research, building rapport with research participants is a process rather than a one-time event and thus requires constant negotiation (Le Dantec and Fox, 2015). Our engagement with PPP study staff began with a presentation we delivered to them about the set-up and aims of the Digital Good project, where study staff were invited to ask questions about the project and their possible involvement. Further points of contact outlined in the study design include a series of workshops with stakeholders involved in the PPP and other case studies (postponed due to the COVID-19 pandemic), where we will further share our findings and invite reflection on our analysis, in order to open up wider dialogues pertaining to issues of ethic and, justice in data-driven biomedical research.

The corpus of data analysed in the present paper consists of ethnographic data and content analysis of data collected from the Web. In the former case, we conducted participant-observations at the Parkinson's Expertise Centre at the Radboud University Medical Centre; attended two of the Event Days organized by the study staff; and conducted six in-depth, semi-structured interviews with members of the PPP study staff. The ethnographic research involved making notes and audio-recordings for the interviews. Web-based data included information available on the public PPP website; monthly newsletters that are sent out to participants and other members of the PPP community; as well as video recordings of the "QueryBox" sessions-videos that the study staff made for the participants covering a variety of themes - which are available on the video sharing platform YouTube. Web-based data became an increasingly important part of our analysis in light of the fact that contact between the study staff and their participants were all web-based for a significant period of time due to COVID-19, and the study staff turned to digital ways of 'giving back'.

All the data were coded and analysed in the qualitative data analysis software package Atlas.ti, and we used Boltanski and Thévenot's justificatory framework (e.g. the six orders of worth) as well as open coding to generate the central analytical themes presented herein. ${ }^{4}$

\section{Giving back in the PPP}

'... so, the idea was, already from the start, that we're asking quite a lot from people, and so that we should also be giving them something back' [C136]

The demands of the civic and the need to give back. The PPP is an ambitious project, both in its scientific and technological objectives. Its primary scientific objective is to evaluate how PD progresses amongst the population of participants and, from there, to understand how they respond to treatment given the presence of known or possible PD biomarkers. Its primary technical objectives are to develop a database consisting of all data collected over the course of the project, as well as to evaluate the role of a wrist-mounted multi-sensor wearable device specifically developed for the project by one of the project's partners, Verily Life Sciences. Participation in the PPP is thus quite onerous: participants are under the constant surveillance of a wearable device, they must submit to periodic invasive testing, and are required to travel sometimes long distances in order to undergo these tests. It is the data that they provide-in the form of digital assessments, biospecimens, questionnaires, MRI recordings, and more-that will constitute the comprehensive dataset the project seeks to compile for future research on PD. And yet, despite the fact that these participants "give so much," as one study staff member phrased it during an interview, the study protocol clearly states that the study staff cannot give participants medicallyrelevant feedback of any kind-let alone the personalized feedback one might expect from participating in a project called the PPP. The PPP is, after all, an effort to develop an infrastructure that will support future research. In a domestic style of doing research, this inability to reciprocate may have gone unnoticed. But following the participatory turn, and in light of the civicparticipatory ideals that the PPP embodies, it becomes painfully conspicuous. We thus find something of a constitutive tension in the $\mathrm{PPP}$ - as a civic-participatory style of doing researchbetween the significant contributions asked of participants and the relative inability of study staff to reciprocate (at least in kind, that is in terms of personalized medical insights).

This tension is something that study staff recognized themselves as a possible problem from the outset of the project, and that they repeatedly expressed in our interviews. To negotiate and resolve this tension, they contrived a number of ways of "giving back" to participants, some of which were planned as part of the study's initial design, and others that emerged along the way as the project progressed. The PPP's study protocol (Bloem et al., 2019) contains several examples of pre-planned modes of giving back. Some are more material in nature, such as the stipulation that for participants who must travel to Nijmegen for their "assessment days" accommodation costs in a hotel will be covered by the project. Along more organizational lines, the project budget also funds a Project Manager, a Communication Lead, and an Engagement Lead, who together are charged with the task of developing ways of giving back to the community of participants. These three positions are atypical for the majority of medical research studies, where funds are generally devoted to clinical assessment and data collection/management. Yet, in designing the PPP, the need for such specialists was recognized as critical to the mission of developing close personal relationships with study participants who must be offered something in return for their time and energy so that their engagement with the study can be experienced as coequals. Indeed, one study staff claimed that fostering "intimacy" with participants and ensuring their involvement 'has actually been our starting point from the first moment, and we simply never wanted to make concessions on that' [C136].

While one may be quick to conclude that the designation of such positions serves only the more instrumental goal of facilitating subject recruitment and retention-which they most certainly contribute to-the "civic" ideals these actors seek to instantiate appear to be more than mere rhetoric. As we were told, there was in fact quite some pushback from a number of "involved parties" about allocating funding for these positions, as well as some of the other provisions:

When I was working on the budget, well, people really wondered about, you know, do you need a communication officer, do you need this, do you have to offer all those people a hotel stay? You know, these are all cost items that put pressure on the budget, but those are really things that we have not wanted to give up. [C109]

In addition to these ways of giving back articulated at the outset of the project, there were also new modes of giving back that took shape as the project progressed. For example, during the Christmas holidays in 2019, members of the study staff wrote personalized Christmas cards to every participant on 
the project-something that one study staff member described to us as one of the 'small things' that she and her colleagues did for the participants 'in between' the other things [C136]. This convergence of pre-planned and emergent modes of "giving back" suggest that members of the study staff had internalized the idea of giving back in such a way that it was a constant consideration throughout the project, indicating that the ideals undergirding a civic style of doing medical research were not merely rhetorical, but were enacted through a distinct set of materials and practices.

Giving back as Fraserian "civic justice". Having briefly discussed a few instances of how study staff have worked to fulfil the civic demands of giving back, we find Nancy Fraser's (1998, 2003) account of justice instructive for articulating two axes along which such diverse modes of giving back can be placed: the provision of information to participants (what Fraser calls "redistribution") and manifestations of respect and appreciation for the knowledge and efforts contributed by study participants (in Fraser's terms, “recognition”). We draw on Fraser's theory of justice because, insofar as it foregrounds participation, inclusivity and equality, it offers a thorough theoretical elaboration of the ideals of justice underpinning the participatory turn more generally, and of Boltanski and Thévenot's (2006) civic order of worth in particular. Indeed, Fraser's is a "civic" theory of justice, insofar as the normative foundation of justice is what Fraser calls "parity of participation", that is, the ability of all adult members of a society to interact with one another as peers $(2003$, p. 36$)$, and thus to substantively contribute to the discourse around which that society is organized. Fraser argues that at least two conditions must be met in order for participatory parity to be achieved. First, equality of access, i.e. a material distribution of resources, which enables a level of independence of participants and ensures they have a "voice"; and second, equality of status, i.e. acknowledgement of respect to all participants and equal opportunity for achieving social esteem. These two conditions or dimensions of justice correspond to the aforementioned dimensions of "redistribution" and "recognition", respectively.

Technologies of redistribution: giving back as "informing". In line with Fraser's two dimensions of civic justice, we qualify the first mode of giving back on the part of PPP study staff as provision of information, which corresponds with Fraser's "redistribution". Indeed, an important characteristic of a domestic style of doing medical research is information asymmetry on the part of patients. In a domestic model, patients are posited as lacking the competencies for understanding medical decision-making processes and are thus expected to put their trust in experts to act in their best interests. In contrast, the qualified experts engaged in the PPP-including physicians, researchers, and study staffopenly share insights and updates about the project and about state-of-the-art Parkinson's research with participants, as well as insights about participant's experiences with the project and with living with PD. They thus attempt to establish information symmetry. Importantly, it is not only good news and helpful tips that they share, but also details about the challenges and setbacks encountered in the course of conducting the PPP, such as problems with recruiting the right demographics of participants, or challenges during the COVID crisis. Such practices of information provision in this civic style of conducting medical research stand in for the otherwise material and economic resources which Fraser stipulates as a central requirement for equality of access, but nevertheless fulfil the same "redistributive" function.

Thus, one interviewee told us that keeping participants informed was viewed as a central mode of "giving back" from the project's earliest days: 'So the idea was from the start that, well, we are asking quite a lot from these people, so we also have to do something in return. And I think the idea was actually already there that, $\mathrm{OK}$, that will be a kind of information platform with videos' [C136]. The technologies of redistribution through which information is shared back with participants in the PPP are many, including the circulation of a monthly newsletter that includes news about the project, updates on recruitment, more general information about recent advances in $\mathrm{PD}$ research, and a roundup of media reports on $\mathrm{PD}$, with clickable links to the original sources for participants to peruse.

The "QueryBox" ("De Vraagbaak" in Dutch), a section of the PPP website where participants can submit questions they have about PD, is another technology of redistribution developed for the PPP. Once there is a critical mass of questions pertaining to a common theme, study staff invite someone with expertise in that particular domain to record a series of short videos where they answer participants' questions. As the QueryBox section of the website states: 'The Parkinson QueryBox is open to everyone, but only (interested) participants in the PPP can submit questions. This is to offer them something extra as a thank you for their interest/participation' [emphasis added].

A cursory view of the topic-areas and list of questions submitted to the QueryBox suggests a community of actively engaged and knowledgeable participants who are also keenly interested in learning more about the complexities of the condition with which they live. For instance, the 2020 PPP Event Day described earlier hosted a live QueryBox session where participants' questions-in this case about the relationship between PD and intestinal flora, and the role faecal transplants might play in treating Parkinson's-indicated a rather high level of scientific literacy amongst attendees. But there are also other, less scientifically complex, questions that participants bring to the QueryBox about living well with such a chronic disease: for example, 'How does your partner remain an equal partner?', and another on 'Parkinson's and Acceptance', which features a psychologist and a person living with Parkinson's who both share strategies for living well with PD. One suggests 'asking for advice and becoming an expert yourself', and another suggests 'participating in research.' (Parkinson op Maat, 2021a).

As is gleaned from these instances of giving back via the QueryBox, the practices of informing can take different shapes, ranging from the sharing of mere technical facts to the imparting of advice of a much more intimate nature. Regardless of genre, however, an interesting element of informing through these technologies of redistribution is that study staff conceptualized them as stand-ins for other possible ways that they might give back to participants, such as providing monetary compensation: 'we reward people in the study [...] not with money,' said one interviewee, 'but with knowledge' [C122]. Nonetheless, as we suggested in the section "The demands of the civic and the need to give back" above, decisions about what knowledge to share back with participants are a source of tension within the project, given that study staff are prohibited from sharing personalized insights and other medically relevant information derived from study assessments. One member of the study staff, when discussing the role of the Study Watch in the PPP, lamented the fact that the wearable was technically capable of collecting participants' step count data-which they thought would have been of great interest to participants, and could have been an acceptable type of data to give back to participants-but that this feature was not activated [C148].

Regardless of the actual implications of this design decision, the very mention of such a concern suggests that study staff were faced with a perceived demand to continuously and actively give something back to participants, often extending beyond those modes of giving back which were identified at the project's outset. 
This came to a head during the PPP Event Day in September 2020 where, for the very first time, PPP researchers actually shared results of a very preliminary analysis of some of the data collected during the first phase of the study: 'it was only really possible this summer for our own researchers to download that data from PEP [the encrypted data warehouse], so to actually do something with the data collected in recent years,' explained a member of the study staff during an interview following the event: 'And yes,' they went on, 'we never even considered for a second not to share that back with the participants' [C109, emphasis added].

Technologies of recognition: giving back as "appreciating". The second mode of giving back we observed in the PPP takes the form of what, building on Fraser's second dimension of civic justice, we call technologies of recognition, and which are signified by expressions of appreciation and gratitude on the part of study staff.' Such technologies of recognition involve making participants feel that they matter, that they are heard and appreciated, and in the case of the PPP, often involve conveying messages of thanks. An example of this mode of giving back is PI Bas Bloem's policy of personally introducing himself to each participant when they come for their initial assessment, shaking their hands and thanking them for their participation [C122]. Bloem has also been known to circulate a video greeting during the holiday season which is sent out to PPP participants. In one such video, he expresses his gratitude for their participation, noting that he is 'proud' but, most of all, 'thankful' (PPP Newsletter 2020-12-24). ${ }^{6}$

A second technology of recognition entails the setting up of spaces that aim to instil a sense of comfort among project participants. The PPP "Expertise Centre" at RUMC is one such physical space, where participants come for their clinical assessments. In designing this space, there was a concerted effort to make the Centre feel "homey" such that participants would forget they were even in a hospital [C105, fieldnotes expertise centre]. Another instance of such physical spaces is the aforementioned arrangement whereby participants and their partners who must travel to Nijmegen for their assessments are put up in a well-appointed 3-star hotel nearby the city centre, breakfast included. Participants are also offered coupons for complimentary lunches for two while at the hospital. Study staff often use the Dutch term 'uitje' [C105] when they describe this arrangement, a word whose English translation suggests that participants are treated to a fun 'day trip' to Nijmegen. And finally, referring back to the opening vignette of this paper, there are also the Event Days that are held for participants, who gather with study staff and other experts and are treated to catered lunches and drinks whilst sharing news and updates about the study.

Technologies of recognition extend to the construction of digital spaces as well. The PPP website has been designed so that users can easily find the information they need. It includes a "Participants Speak" section where participants share their own experiences with the PPP and with living with PD more generally (Parkinson op Maat, 2021b). The website also has a link to the PPP Help Desk, which can itself be approached as a type of recognition work that study staff carry out. The Helpdesk is a hotline of sorts that PPP participants can call with any questions they have, and it is staffed by a team of "assessors"-a group primarily made up of eight specialist research nurses on the PPP -who take turns working 4-h shifts at the Help Desk as part of their daily duties. The Helpdesk is also a key touchpoint for participants to get in touch with their personal assessor. Every participant is paired with one assessor who is their contact point and by whom they are followed for the duration of the project.
This work of pairing each participant with a personal assessor is an additional technology of recognition built in to the PPP, as evidenced by the following except:

One of the things we heard back [from our panel of patient advisors] is that people don't want to be numbers, and certainly not if you participate in scientific research that you do voluntarily. You just want to have the feeling that you belong somewhere and that you make a difference. And if you have an assessment day where you go to different people all day to collect your data, you do not feel as if you are important and that you are contributing to something. So that is really the reason that we have chosen to train our assessors so that they can do everything themselves; so that a participant has one point of contact and also builds a kind of relationship with that assessor [C109, emphasis added].

However, just as there are tensions about how best to mobilize technologies of redistribution, so too do technologies of recognition present study staff with certain tensions within the close personal relationships they build with participants. As one study staff member put it, 'a lot of people ask very personal questions' when they send in questions for the QueryBox, 'they send their entire medication schedule and then they say, "What can I do to prevent [the medication] from wearing off?" It is up to the study staff, then, to inform participants that such questions are best addressed to their neurologist, and that the QueryBox is intended for more general questions about Parkinson's: 'but sometimes people are so desperate for an answer (...) that they just think: 'I'll just try" [C136] This is indicative of the aforementioned constitutive tension in the project, where study staff feel a need to give back, but are limited to only certain bounded modes of giving back, whether in terms of information or recognition, a fact made all the more complex by the close relationships study staff seek to build with participants.

Though the newsletter is mainly meant to inform participants, it doubles as a venue for conveying thanks and creating bonds with them. A new assessor introduces herself through the newsletter, answering some questions on how she got there and her motivation, but also how she spends her spare time. Another example was an assessor who shared her experience working as a nurse in the intensive care unit during the first wave of COVID19. Personal stories of participants are also shared through the newsletter: 'This summer we would like to dedicate a theme to "living with Parkinson's", with a positive approach: what are you still able to do and what do you enjoy doing in daily life? We are looking for people with Parkinson's that we can interview about their hobbies' (PPP Newsletter, June 2020).

Where the ideas of giving back as informing were partially discussed as being requested by participants (this was an outcome of the participants panel), giving back as recognition is usually done on the initiative of the study staff:

Yes, at least the suggestion of wanting to have more knowledge and get in touch with each other [other Parkinson patients], I think that came from a panel. And that we then brought that together ourselves into: okay, well, maybe we should organize an event to thank all our participants and put those two things together. [C109]

Giving back as recognition is meant to re-establish reciprocal ties between study staff and study participants, whose collective action is a precondition for the success of the project. We have seen that the study staff cannot discuss the success of the project without giving recognition to the contribution of the participants to that success. 


\section{Discussion and conclusion: From domestic to civic to successful domestic-civic compromises}

We began this paper by discussing an ongoing "participatory turn" within the sphere of medical research, from a "domestic" model that operates on an established hierarchy between qualified medical professionals and passive patients/research participants, to one that is more "civic" in nature, and which emphasizes the active participation of patients as co-equal participants in research, levelling the playing field as it were. Drawing on extensive fieldwork and interviews with study staff within the PPP -a large study which was designed with a civic-participatory philosophy in mind-we argued that enacting the civic in a context traditionally coordinated domestically is not an easy task. Namely, in the framework of a study which requires that participants "give" abundantly (time, samples and data) over a period of two years, a persistent concern manifests itself on the part of study staff regarding what and how to "give back", or, regarding how to fulfil the imperative of reciprocity presupposed by the civic. Indeed, while an obvious way of giving back would have been in the form of personalized insights based on the data collected in the project, generating such insights is not one of the aims of the PPP, which seeks to build a comprehensive dataset for future research and identify new general (not personal) biomarkers. Study staff had their hands tied in this sense, and communicated this limitation of the project clearly and continuously to participants. As we showed, study staff adapted to the demands of the civic style of research and this inherent limitation on what could be given back by finding a number of creative workarounds for giving back.

We claimed that these different ways of giving back can be understood in terms of Nancy Fraser's theory of justice as "parity of participation", which dovetails with Boltanski and Thévenot's own characterization of the civic order of worth. In this reading, study staff in the PPP sought to give back to participants in two ways that align with Fraser's two conditions of justice as equality of access (redistribution) and equality of status (recognition). The condition of redistribution was fulfilled by providing information to participants in the form of, for example, a monthly newsletter on the project and scientific updates, a "QueryBox", where participants could ask specific questions about living with $\mathrm{PD}$, and even, unintended in the protocol design, communication of preliminary data analyses (albeit not personalized ones). The condition of recognition was fulfilled by expressions of gratitude and appreciation in the form of, for example, personal encounters with Principal Investigator Bas Bloem, attention to material comfort around assessment days, Christmas messages, pampering Event Days, designated assessors throughout the study, and a specialized helpdesk that participants could call with any questions concerning their participation. These efforts can be seen as a means of ensuring that the promises of the participatory turn and its demands of justice remain commensurate with the reality of doing a newer, more civic style of medical research.

Beyond critical unmasking approaches: value pluralism and compromises. Our analysis makes several contributions. Importantly, while, as others, we are interested in the effects of the participatory turn in health and medicine, we have sought to move beyond the impulse to debunk or unmask the civicparticipatory turn in medical research, which is a common strategy in much critical research (Hansen, 2016; Latour, 2004; Lehtiniemi and Ruckenstein, 2019; Sharon, 2017). Here, discourses of participation are often exposed as appealing to ideals of equality and empowerment while in practice passing on much of the labour of medical research and care to patients themselves in order to cut costs, or positioning them as mere sources of valuable medical data who willingly give up their personal information with the (unsubstantiated) promise that they will benefit from their so-called "equal participation". Rather than seeking to unmask, we bracketed off assumptions concerning authentic and inauthentic appeals to and enactments of the participatory turn. This allowed us to explore the issues and challenges that arise in the process of ensuring that ideal and practice align in a civic style of doing medical research, and how these were addressed by study staff, which may not be visible in a critical-unmasking approach. For example, many practices of giving back that we have presented here might easily be interpreted in a critical-unmasking approach as mere recruitment and retention strategies that involve some degree of deceit. Instead, we have tried to show that they may also, or better, be understood as an attempt to fulfil the demands of reciprocity and justice as distribution or recognition made by the civic order of worth, which simultaneously help increase retention rates. This is of course not to say that there are no so-called inauthentic or deceitful mobilizations of discourses of participation in the current practices of health and medicine, but that the effects of these discourses are more multifaceted and complex than an unmasking approach suggests.

The framework of orders of worth that we have drawn on in this article is particularly helpful for identifying this multifacetedness. First, because it calls for this "bracketing off" of the researcher's critical gaze to begin with. It promotes a naïve inquisitive disposition as it were, which seeks to engage seriously with the moral statements and justifications that actors pronounce (Boltanski et al., 2014). But also, because it assumes a rich value pluralism (there are numerous orders of worth) and both a value agonism and complex value compromises which are not accounted for in a critical-unmasking approach. As discussed, the orders of worth framework assumes that orders can travel, that there can be "importations" and "transportations" of orders from one setting to another. Thus, family life, the paradigmatic setting of the "domestic" order (hierarchy and respect), can also be coordinated along a "civic" order (democratically), or along an "industrial" order (efficiently, like a factory). Orders can also clash and compete in any given setting, and they can become more or less dominant in different historical contexts. It is in this sense that we understand the participatory turn in health and medicine as an importation and rise to dominance of a civic style of doing research in a setting which had previously been coordinated along the demands of a domestic order. As argued elsewhere (Sharon, 2021), this value agonism and dynamism opens up a different line of enquiry where questions focus on the effects of importations. Here, as we have seen, this approach allowed us to identify the tension that the importation of the civic order into a traditionally domestically coordinated context generated for PPP study staff and how they sought to resolve it.

But value agonism, in this framework, does not necessarily result in a complete appropriation or hegemony of one order at the expense of another. Often, what Boltanski and Thévenot call "compromises" between orders ensue. They write, 'A compromise suggests the possibility of a principle that can take judgments based on objects stemming from different worlds and make them compatible. It aims at a common good that transcends the two different forms of worth in presence by including both of them' (Boltanski and Thévenot, 2006, p. 278). Similarly, rather than a univocally civic style of doing research, what we observed in the PPP may more accurately be seen as a particular civic-domestic compromise, insofar as not all elements of the domestic order were expunged. Indeed, while the domestic order is characterized by hierarchy and paternalism, it also implies a duty of care and responsibility for those on lower echelons of that hierarchy, such as of medical professionals' towards patients-expressions of which were consistent among our interviewees. These core norms 
of medical research and care survived, so to speak, the rise to dominance of the civic in the case of the PPP. It is premature to generalize without further investigation into how participants experience their involvement in the PPP, a group which was not included in our current findings. Nonetheless, we think that, at least from the study staff s perspective, the PPP seems to have achieved a good civic-domestic compromise, where both civicreciprocity, equality and recognition co-exist with domestic care and responsibility. However, to label the project a 'successful' compromise would require more research on the experience of the participants. ${ }^{7}$

Towards an evaluation of successful domestic-civic compromises. This brings us to what we see as a potentially important contribution to critical studies of the participatory turn in particular, and of health and medicine in general. Reaching this type of civic-domestic compromise is not a given, as has been carefully foregrounded by Annemarie Mol's (2008) work on how attempts to rectify medical paternalism, drawing on discourses of civic equality and participation, often ensue in the sacrifice of a "logic of care" at the altar of the "logic of choice". In other words, vigilance is crucial; and learning from successful compromises is key. This raises several questions that require further research in our case. For example, supposing the PPP can be considered a good civic-domestic compromise, what was it about its set-up that contributed to this success? As we have seen, substantial resources in the PPP were allocated to "giving back" from the outset. Not every project will have the resources required to engage participants to this extent. Furthermore, study staff were also at quite some liberty to think along and innovate in terms of ways of giving back. Yet this level of involvement of assessors and coordinators in shaping the PPP is not common. Finally, the charismatic figure of Bas Bloem, and his fervent belief in participatory medicine, seems to have been a source of inspiration for most of our interviewees. Conversely, what, if anything, about the PPP's set-up detracted from its success as a civic-domestic compromise or even a civic endeavour? The notion of "participant as co-expert" that is inherent to the participatory ideal in medicine is not fully realized in the PPP, due to the main objective of the project of building a data repository. This leaves the question of how far a civic style of doing research can be pushed in the context of public-private partnerships or studies that seek to develop infrastructures like the PPP. Finally, which other compromises may be at work and made visible once we adopt this framework? As mentioned, the civic and the domestic are only two of numerous orders of worth that have been identified by Boltanski and Thévenot and other scholars using this framework.

These questions and others require further investigation, but point to what we see as an important potential to contribute to critical studies of health and medicine. By looking at the ideal of the participatory turn in this project as a civic-domestic compromise rather than an inauthentic mobilization of the civic order, we can begin to describe not only what the participatory turn may look like in practice, but also to rethink what the participatory turn should look like in practice. We have seen that for the study staff of the PPP, enacting the participatory turn involved resolving new demands. Understanding what these demands entail, and the challenges of meeting them, could be helpful for others seeking to practice participatory health and medicine. We have shown that enacting the participatory turn involves more than just welcoming input from patients. More than this, it may require a complex balance of patient empowerment, recognition and reciprocity with personal bonds and care. More research needs to be done into how healthcare professionals can do the work of balancing these values as well as managing the expectations of the participants about their role as participants, as well as how we as scientists can evaluate successful civic-participatory projects. By looking further than whether a participatory project meets the demands of the 'participatory' label, we may arrive at a better idea of what a successful civic-participatory project should involve. We hope our findings offer a step in this direction.

\section{Data availability}

The datasets generated during and/or analysed during the current study are not publicly available in order to respect the privacy of the interviewees, but are available from the corresponding author on reasonable request.

Received: 2 June 2021; Accepted: 2 November 2021; Published online: 01 December 2021

\section{Notes}

1 All interviews in this paper have been pseudonymised and given a random key number. Most of the interviews were conducted in Dutch and have been translated by the interviewer, i.e. one of the authors of this paper.

2 As interviewers we were also corrected on several occasions, not to speak of study participants as "patients" but as "participants".

3 While in this article we focus only on these two orders of worth, this is part of a larger research project where the orders of worth framework is used in a more conventional way. There, we use it to map the different justifications mobilized by different stakeholders involved in what we call the "Googlization of health", or the entrance of large consumer tech corporations such as Google and Apple into the realm of health of medicine (see Sharon, 2018) and https://www.ru.nl/ptrs/research/research-projects/ digital-good/). The medical study discussed in this article is one of the case studies in this larger project.

4 See also Ylä-Anttila and Luhtakallio (2016) for an example of this type of "justification analysis".

5 Recognition, just as esteem and respect, might be seen as values that are more at home in the domestic than the civic order of worth in Boltanski and Thévenot's framework, where they act as signs of proximity to worth in a clear hierarchy. But we contend, in line with Fraser, that the recognition provided by the PPP study staff is more civic than domestic. Fraser is interested in recognition insofar as its absence presents an obstacle to participatory parity. She conceptualizes recognition as a moral question about civic justice (this, in disagreement with theorists such as Charles Taylor and Axel Honneth, who she argues offer a Hegelian conception of recognition framed as an ethical question about self-realization). Similarly, in the context of the PPP, recognition works to enable study participants to participate in the rich sense of participatory parity, to interact with experts as peers, rather than to show respect for a given hierarchy.

6 Featured in the newsletter of 24-12-2020 16:25, accessible through: https:// www.youtube.com/results? search_query=parkinson + op + maat + eindejaars

7 The PPP's exceptionally high retention rate (99\% at the time of writing) suggests-so long as one does not fall back into an unmasking approach-that participants are to some extent satisfied with this experience.

\section{References}

Beier K, Schweda M, Schicktanz S (2019) Taking patient involvement seriously: a critical ethical analysis of participatory approaches in data-intensive medical research. BMC Med Inform Decision Mak 19(1):90. https://doi.org/10.1186/ s12911-019-0799-7

Berg M, Mol A (1998) Differences in medicine: unravelling practices, techniques, and bodies. Duke University Press.

Bloem BR, Marks WJ, Silva de Lima AL, Kuijf ML, van Laar T, Jacobs BPF, Verbeek MM, Helmich RC, van de Warrenburg BP, Evers LJW, intHout J, van de Zande T, Snyder TM, Kapur R, Meinders MJ (2019) The Personalized Parkinson Project: examining disease progression through broad biomarkers in early Parkinson's disease. BMC Neurol 19(1):160. https://doi.org/10.1186/ s12883-019-1394-3

Bloem BR (2011) From God to guide. https://www.youtube.com/watch?v=LnD Wt10Maf8\&t $=194 \mathrm{~s}$

Boltanski L, Honneth A, Celikates R (2014) Sociology of critique or critical theory? Luc Boltanski and Axel Honneth in conversation with Robin Celikates (trans: Susen S), The spirit of Luc Boltanski: essays on the 'Pragmatic Sociology of Critique'. Anthem Press, London, pp. 561-589 
Boltanski L, Thévenot L (2006) On justification: economies of worth. Princeton University Press, Princeton

Collins S, Britten N, Ruusuvuori J (2007) Patient participation in health care consultations: qualitative perspectives: qualitative perspectives. McGraw-Hill Education, London

Corrigan O, Tutton R (2006) What's in a name? Subjects, volunteers, participants and activists in clinical research. Clin Eth 1(2):101-104. https://doi.org/ $10.1258 / 147775006777254524$

Dickenson D (2013) Me medicine vs. we medicine: reclaiming biotechnology for the common good. Columbia University Press, New York

Eliasoph N, Lichterman P (2003) Culture in interaction. Am J Sociol 108(4):735-794. https://doi.org/10.1086/367920

Epstein S (1995) The construction of lay expertise: AIDS activism and the forging of credibility in the reform of clinical trials. Sci Technol Hum Values 20(4):408-437. https://doi.org/10.1177/016224399502000402

Eysenbach G (2008) Medicine 2.0: social networking, collaboration, participation, apomediation, and openness. J Med Internet Res 10(3):e1030. https://doi.org/ $10.2196 /$ imir. 1030

Fraser N (1998) Social justice in the age of identity politics: redistribution, recognition, and participation. In: Peterson GB (Ed.) The Tanner lectures on human values, vol 19. The University of Utah Press, Salt Lake City, pp. 1-67

Fraser N, Honneth A, Golb J (2003) Redistribution or recognition?: a political-philosophical exchange. Verso, London

Hansen MP (2016) Non-normative critique: Foucault and pragmatic sociology as tactical re-politicization. Eur J Soc Theory 19(1):127-145. https://doi.org/ $10.1177 / 1368431014562705$

Harris A, Wyatt S, Kelly SE (2013) The gift of spit (and the obligation to return it). Information. Commun Soc 16(2):236-257. https://doi.org/10.1080/1369118X. 2012.701656

Hood L (2009) A doctor's vision of the future of medicine. Newsweek. https:// www.newsweek.com/doctors-vision-future-medicine-80793

Jacobs B, Popma J (2019) Medical research Big Data and the need for privacy by design. Big Data Soc 6(1):205395171882435. https://doi.org/10.1177/ 2053951718824352

Kremer JA, Van Der Eijk M, Aarts JW, Bloem BR (2011) The individual formerly known as patient, TIFKAP. Minerva Med 102(6):505

Latour B (2004) Why critique has run out of steam. Crit Inq 30(2):225-248. https:// doi.org/10.1086/421123

Law J, Mol A (2002) Complexities: social studies of knowledge practices. Duke University Press.

Le Dantec CA, Fox S (2015) Strangers at the gate: gaining access, building rapport, and co-constructing community-based research. In: Proceedings of the 18th ACM conference on computer supported cooperative work \& social computing, Association for Computing Machinery, pp. 1348-1358.

Lehtiniemi T, Ruckenstein M (2019) The social imaginaries of data activism. Big Data Soc 6(1). https://doi.org/10.1177/2053951718821146

Mol A (2008) The logic of care: health and the problem of patient choice. Routledge, Abingdon

Myskja BK (2007) Lay expertise: why involve the public in biobank governance? Genom Soc Policy 3(1):1. https://doi.org/10.1186/1746-5354-3-1-1

Nielsen KD, Langstrup H (2018) Tactics of material participation: how patients shape their engagement through e-health. Soc Stud Sci 48(2):259-282. https:// doi.org/10.1177/0306312718769156

Parkinson op Maat (2021a) Parkinson Vraagbaak. https://www.parkinsonopmaat. nl/parkinson-vraagbaak. Accessed 12 May 2021

Parkinson op Maat (2021b) Deelnemers aan het woord-ParkinsonOpMaat. https://www.parkinsonopmaat.nl/studies/actueel/deelnemers-aan-het-woord. Accessed 31 May 2021

Petersen A, Lupton D (1996) The new public health: health and self in the age of risk. Sage Publications, Thousand Oaks, p. xvi, 208

Pols J (2014) Knowing patients: turning patient knowledge into science. Sci Technol Hum Values 39(1):73-97. https://doi.org/10.1177/ 0162243913504306

Prainsack B (2009) The participatory turn in medicine-which letter in the alphabet? The Privacy Report. https://theprivacyreport.com/2009/11/04/theparticipatory-turn-in-medicine-which-letter-in-the-alphabet/

Prainsack B (2011) Voting with their Mice: personal genome testing and the "participatory turn" in disease research. Account Res 18(3):132-147. https:// doi.org/10.1080/08989621.2011.575032

Prainsack B (2014) The powers of participatory medicine. PLoS Biol 12(4):e1001837. https://doi.org/10.1371/journal.pbio.1001837

Prainsack B (2017) Personalized medicine: empowered patients in the 21st century? NYU Press, New York

Prior L (2003) Belief, knowledge and expertise: the emergence of the lay expert in medical sociology. Sociol Health Illn 25(3):41-57. https://doi.org/10.1111/ $1467-9566.00339$
Rabeharisoa V (2003) The struggle against neuromuscular diseases in France and the emergence of the "partnership model" of patient organisation. Soc Sci Med 57(11):2127-2136. https://doi.org/10.1016/S0277-9536(03)00084-4

Sharon T (2015) Healthy citizenship beyond autonomy and discipline: tactical engagements with genetic testing. BioSocieties 10(3):295-316. https://doi.org/ 10.1057/biosoc.2014.29

Sharon T (2017) Self-tracking for health and the quantified self: re-articulating autonomy, solidarity, and authenticity in an age of personalized healthcare. Philos Technol 30(1):93-121. https://doi.org/10.1007/s13347-016-0215-5

Sharon T (2018) When digital health meets digital capitalism, how many common goods are at stake? Big Data Soc 5(2):2053951718819032. https://doi.org/ $10.1177 / 2053951718819032$

Sharon T (2021) From hostile worlds to multiple spheres: towards a normative pragmatics of justice for the Googlization of health. Med Health Care Philos. https://doi.org/10.1007/s11019-021-10006-7

Topol E (2016) The patient will see you now: the future of medicine is in your hands. Hachette UK, London

Woolley JP, McGowan ML, Teare HJ, Coathup V, Fishman JR, Settersten RA, Sterckx S, Kaye J, Juengst ET (2016) Citizen science or scientific citizenship? Disentangling the uses of public engagement rhetoric in national research initiatives. BMC Med Eth 17(1). https://ora.ox.ac.uk/objects/uuid:f55427c56680-44c6-9c4a-1c155dbfc999

Wyatt S, Harris R, Wathen N (2010) Health(y) citizenship: technology, work and narratives of personal responsibility. In: R. Harris, S. Wyatt, N. Wathen (Eds.), Configuring health consumers: health work and the imperative of personal responsibility, Palgrave Macmillan, pp. 1-10.

Wyatt S, Harris A, Adams S, Kelly SE (2013) Illness online: self-reported data and questions of trust in medical and social research. Theory Cult Soc 30(4):131-150. https://doi.org/10.1177/0263276413485900

Ylä-Anttila T, Luhtakallio E (2016) Justifications analysis: understanding moral evaluations in public debates. Sociol Res Online 21(4):1-15. https://doi.org/ $10.5153 /$ sro.4099

\section{Acknowledgements}

We would like to thank all the study staff of the PPP who contributed to this paper. This work was supported by the European Research Council, Grant Number 804989.

\section{Competing interests}

The authors declare no competing interests.

\section{Informed consent}

Informed consent was obtained from all participants of this study.

\section{Ethical approval}

This study has been approved by the 'Ethics Assessment Committee Humanities (EACH) of Radboud University. All research was performed in accordance with relevant guidelines/regulations, including the Declaration of Helsinki.

\section{Additional information}

Correspondence and requests for materials should be addressed to Lotje E. Siffels.

Reprints and permission information is available at http://www.nature.com/reprints

Publisher's note Springer Nature remains neutral with regard to jurisdictional claims in published maps and institutional affiliations.

\section{(i)}

Open Access This article is licensed under a Creative Commons Attribution 4.0 International License, which permits use, sharing, adaptation, distribution and reproduction in any medium or format, as long as you give appropriate credit to the original author(s) and the source, provide a link to the Creative Commons license, and indicate if changes were made. The images or other third party material in this article are included in the article's Creative Commons license, unless indicated otherwise in a credit line to the material. If material is not included in the article's Creative Commons license and your intended use is not permitted by statutory regulation or exceeds the permitted use, you will need to obtain permission directly from the copyright holder. To view a copy of this license, visit http://creativecommons.org/ licenses/by/4.0/

(C) The Author(s) 2021 